\title{
Congenital Hematological Disorder
}

National Cancer Institute

\section{Source}

National Cancer Institute. Congenital Hematological Disorder. NCI Thesaurus. Code C104003.

A disorder of the blood that is present at birth. 